\title{
The Performance Evaluation of SMA Spring as Actuator for Gripping Manipulation
}

\author{
Made Andik Setiawan \\ Timah Manufacture Polytechnic, University of Bangka Belitung, \\ Jln. Timah Raya, Air Kantung, Sungailiat - Bangka, Indonesia \\ E-mail:made_andik_s@plasa.com
}

\begin{abstract}
This paper is to present the evaluation of a TiNi Shape Memory Alloy (SMA) spring as actuator for the gripping manipulation. The SMA spring employed was a TiNi tensile spring which has a diameter of $50 \mathrm{~mm}$ wire and 350 gram hanging mass. The gripper fabricated consists of two fingers and each finger is actuated by the SMA spring. The total angular displacement of the gripper is $30^{\circ}$. The power consumptions, the movements and force generations experimentations have been conducted. The DC signal and PWM signal with 12, $12 \mathrm{~Hz}, 25 \mathrm{~Hz}, 125 \mathrm{~Hz}, 250 \mathrm{~Hz}$ and the $1150 \mathrm{~Hz}$ have been employed for driving the SMA. The experimental results indicated that the $125 \mathrm{~Hz}$ of PWM signal was likely to be had a better performance than the other signals. The $125 \mathrm{~Hz}$ PWM signal generated faster movement, lower power consumption, and constant rate of force. In this study, closed-loop control for gripping manipulation was also conducted. The close loop controller used is PID controller. The Ziegler-Nichols method has been used to predict the optimal gain of the controller, but the best performance was determined by experimentally tuning of the gains. The experimental results indicated that the PID controller is likely to be reliable controller for gripping manipulation of the SMA spring. To obtain the better performance, it is important to consider the SMA cooling responses and the long time of retain in certain position of the gripper.
\end{abstract}

Keywords: PID, shape-memory-alloy spring, gripper, PWM, Lab-View

\section{INTRODUCTION}

\section{Shape Memory Alloy and Its Application}

In recent years, much effort has been devoted to design, construction and control in micro and nano scale. In electronic component technology, the micro and nano technology has been widely developed to produce an integrated circuit (IC) component and micro-processor (chip). However, the development of circuit technology in micro and nano scale has not been followed in other areas especially in actuator, sensor, material and mechanical technology. Shape memory alloy (SMA) is one of the emerging actuator for MEMS (Micro-electro-mechanical system) and NEMS (Nano-electro-mechanical system) instead of piezoelectric, electrostatic, thermopneumatic, magnetic, electrohydrodynamic, and bimetallic effects [1]. Conventional technologies such as electric, hydraulic, and pneumatic actuators have difficulties generating significant forces when their size and weight are scaled down. However, SMA actuators can attain a high strength to weight ratio that makes them ideal for miniature applications [2]. SMA actuators has a good high power/ weight ratio, produce a large displacement in a limited space, it has good temperature transformation, low power consumption and an excellent mechanical properties such as ductility and toughness $[3,4]$.

Note: Discussion in impected before December, $1^{\text {st }} 2007$, and will be publiced in the "Jurnal Teknik Elektro" volume 8, number 1 March 2008 .
The SMA responds the temperature by changing their shape and generates force and displacement. The Figure 1 illustrates that how the SMA responses the heating and generates the changing on their shape. The design of the pneumatically micro-gripper is actuated by SMA is shown in Figure 2.

The SMA is inter-metallic alloys, so they can be driven by electrical current via Joule heating which is easy and efficient way [5]. The shape memory alloy usually consists of single piece of metal, and spring is one of their forms [5].The SMA spring has been used on many applications extensively in medicine and robotics. According to Wang, Z.G, et.all [6], the SMA spring can be directly actuated by electrical current. They investigated the characteristics of the SMA spring by the alternating and direct current electrothermal driving. As the results of their experiments, Wang, Z.G, et.all [6] state that "the most important two-way shape memory effect characteristic is its magnitude and response time".

The electrical actuation of the MEMS has been widely considerate by many researchers. The electrical actuation on many application of MEMS are voltage based controller [7], current based controller [8] and frequency based controller [9]. In this study, the characterizations of the SMA spring were investigated by comparing those actuations methods. 


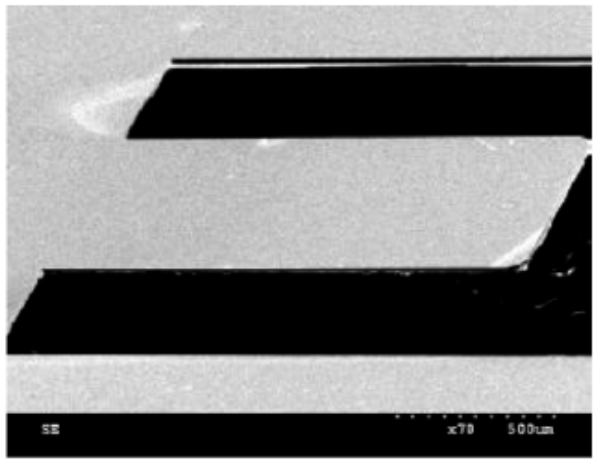

(a)

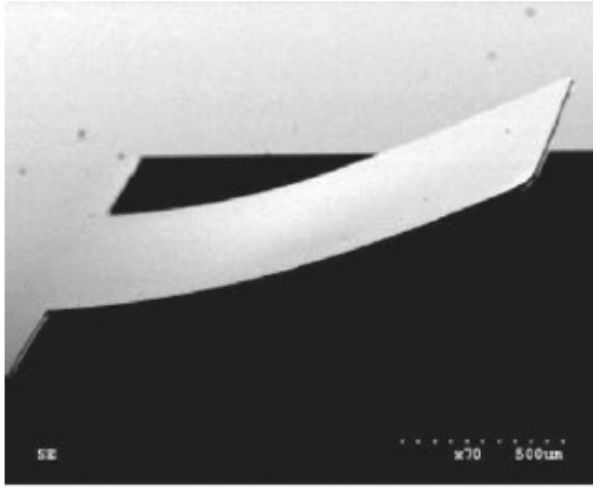

(b)

Figure 1. (a) Cantilever structure with a thickness of $15 \mathrm{~mm}$ fabricated by the conventional MEMS process; (b) bending of the cantilever structure deposited with NiTi films during heating [10].
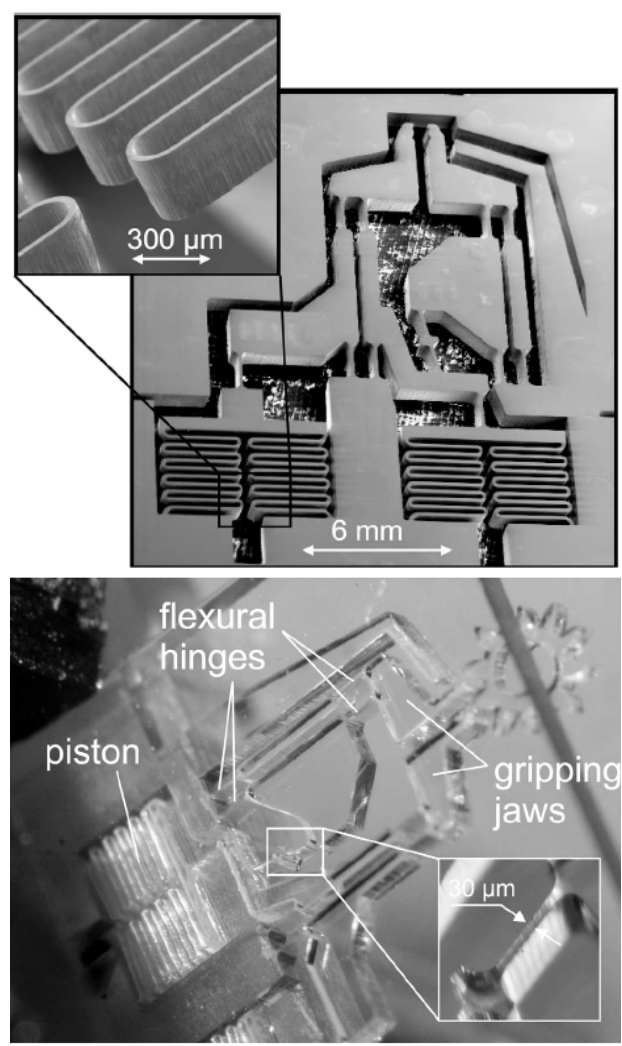

Figure 2. Pneumatically driven micro-gripper [11].

\section{PulseWidth Modulation}

PulseWidth Modulation (PWM) has been widely used on the motor control speed applications, valve and many applications. It consists of pulses train with value of frequency. The most important parameter in the PWM is a duty cycle. A duty cycle is comparison between 'high logic' time and period of the signal.

PWM has been widely used in microelectromechanical system (MEMS) applications. The advantage using of the PWM is power consumptions saving [12], it can be applied with low voltage level and high current which are not very good operation conditions for the power electronic components and also it has "better performance in term of controllability and linearity" [13]. According to Duggirala, R. and Lal [9], Dubois, Ph., Guldimann, B., Gretillat,M.A., and de Rooij, N. F [12] and also by Xie, J., Shih, J. and Tai, Y.C [8], the PWM signal has been employed as a controller for adjusting the flow rate of the microvalve. They investigated the flow rate characterization of the microvalve actuated by different duty cycles and frequencies. Referring to Cordova, F.G., Coronado, J.L., and Gonzhlez, A.G [2], a novel technique has been implemented for SMA drive. It consists of a PWM wave with a carrier of $200 \mathrm{KHz}$ frequency.

\section{Design of the SMA Gripper}

Gripping principles include vacuum suction, shape memory effect, piezo actuation, magnetic actuation, electrothermal effect and also laser trapping. Menciassi, A. et all [14] has published the gripper mechanism which the actuation is provided by SMA and driven by an electrical. The other grippers have also been published and developed by researcher for any purposes, such as the electrostatic microgripper by Millet, O., et.all [15], Peirs, J., Reynaerts, D., and Van Brussel, H., developed the endoscopic tip actuator [16], the microgripper for holding the chip by Cecil, J., and Gobinath, N. [17], the electric piston for the gripper finger by Cordova, F.G., Coronado, J.L., and Gonzhlez, A.G [2], micro four gripper finger by Sebastian et.all [18], SMA micro-gripper by Xie et.all [8] and also asymmetric gripper by Menciassi et.all[14]. 

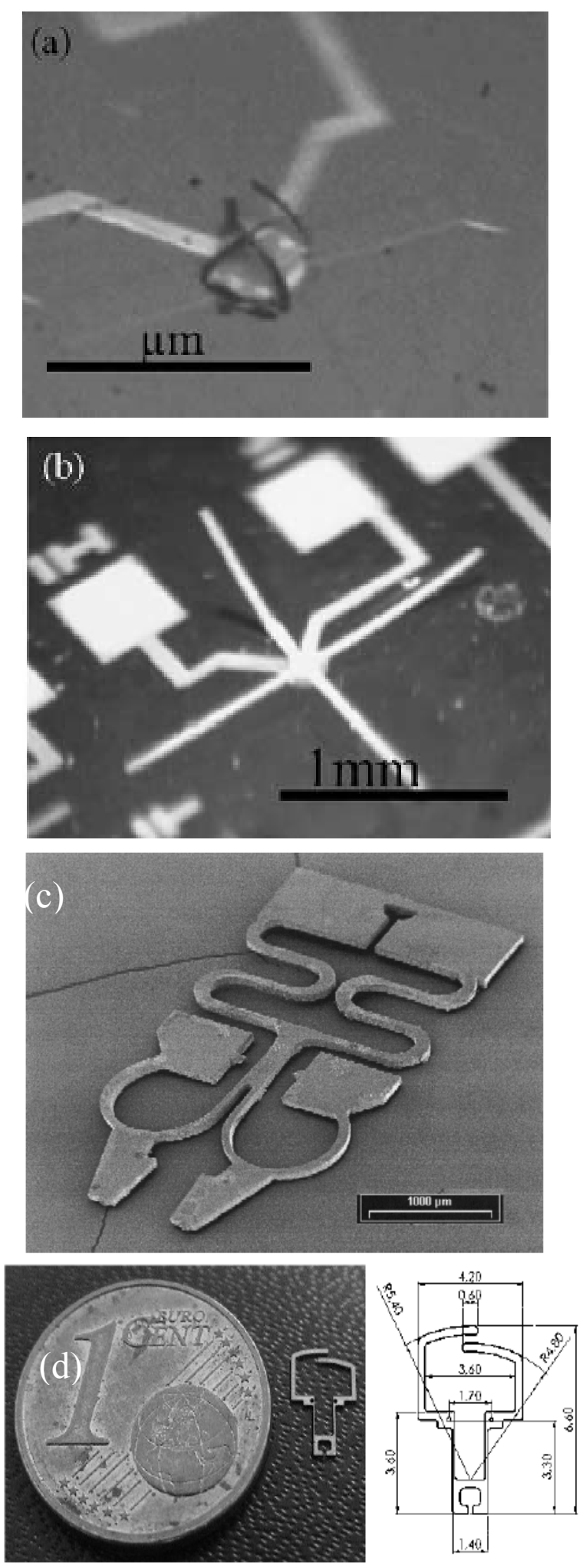

Figure 3. (a) Micro four-finger actuators with different configurations in different batches after the release process. The dimensions of Nafion layer in each finger of the actuators are $\mathrm{w}=30,1=300$, and $\mathrm{t}$ $=0.2 \_\mathrm{m}$ in (a), and $\mathrm{w}=30,1=1000$, and $\mathrm{t}=0.2 \_\mathrm{m}$ in (b) [18]; (c) SMA Micro-gripper [19]; (d) Prototype of the asymmetric gripper and dimensions (in mm) [14].

\section{PREPARATION OF EXPERIMENTAL}

\section{A Two Finger Gripper}

The movement of the gripper in this study is actuated by a shape memory alloy spring. The gripper mechanism (in $\mathrm{mm}$ ) and working principle are shown in Figure 4 and 5 respectively. The material of the gripper is with a thickness of $2 \mathrm{~mm}$ Aluminum (Al). The hole of A and B were used as a center of movement of the gripper. This hole was also used to assemble the position sensor. The bottom holes were used for the spring hook.

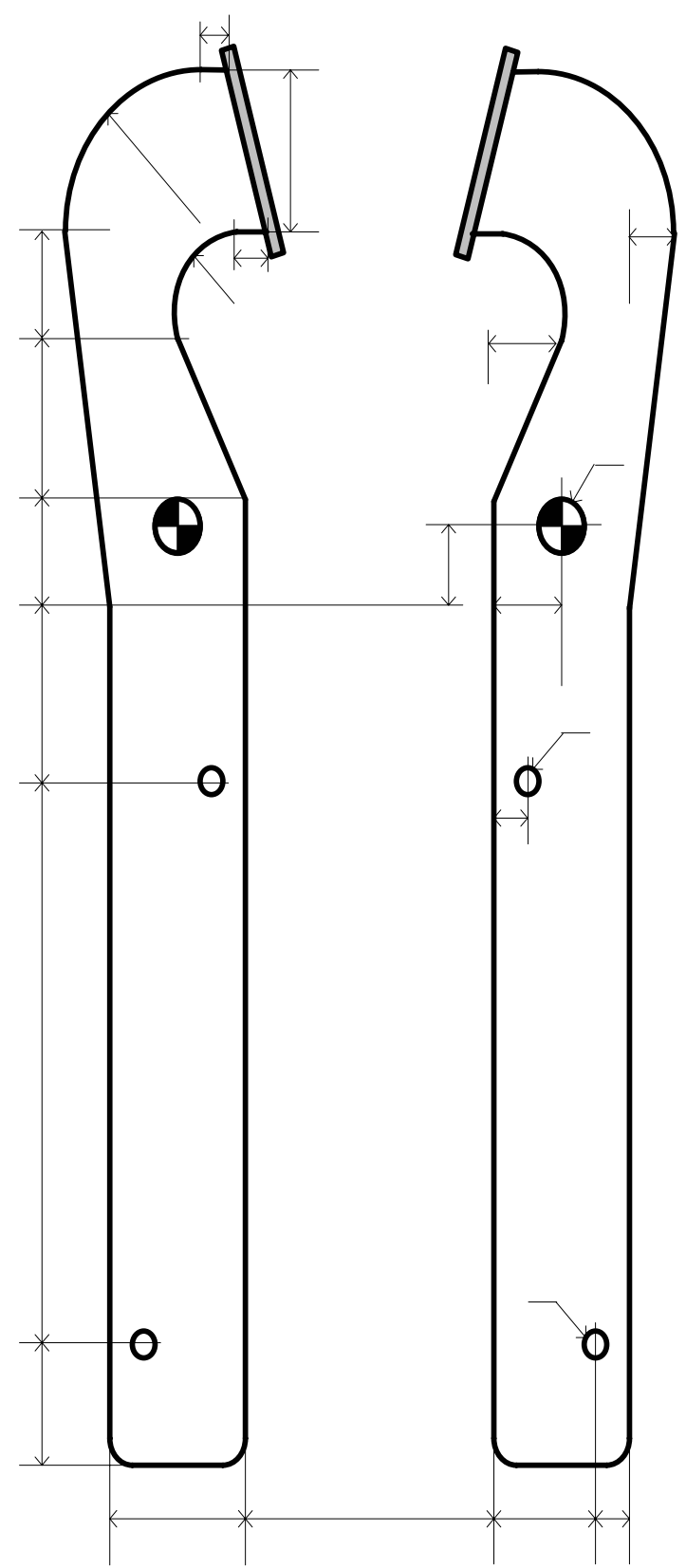

Figure 4. Gripper consisting of two fingers 


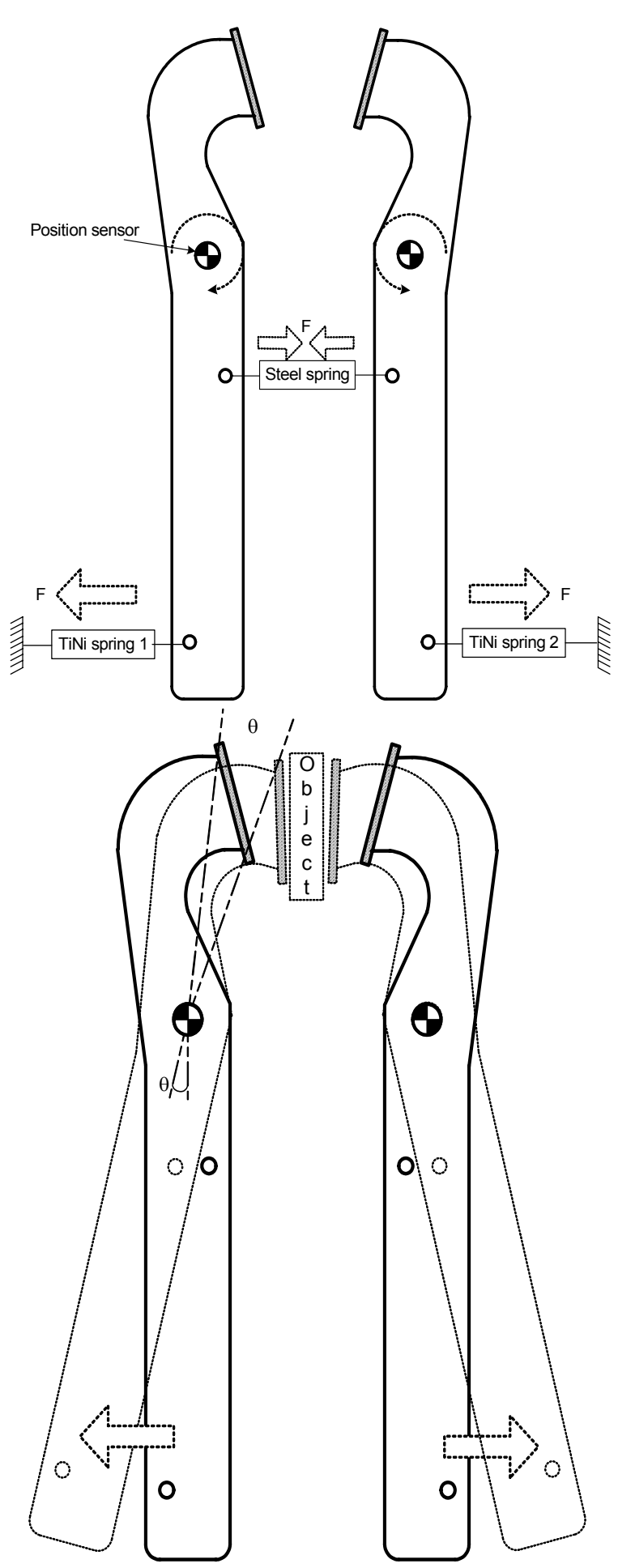

Figure 5. The working principle of the gripper

\section{Position Sensor}

The position sensor used was a rotary potentiometer with a $5 \mathrm{~K} \Omega$ of resistance. This potentiometer has shaft diameter of $5.5 \mathrm{~mm}$, shaft length of $10 \mathrm{~mm}$ and linear resistance (type B). The total rotation of this potentiometer is $300^{\circ}$. The work envelope of this position sensor is depicted in Figure 6.

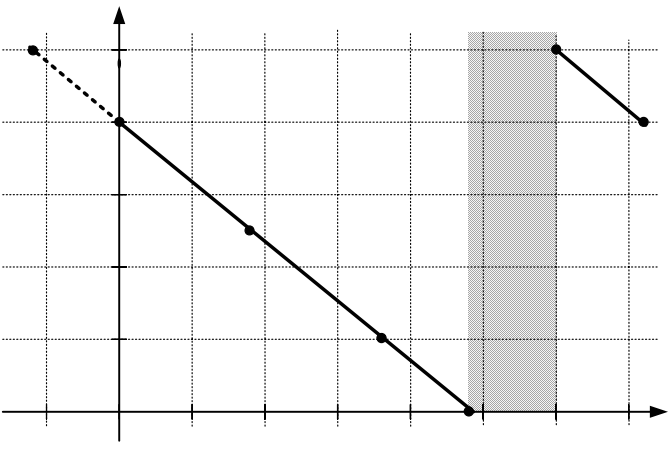

Figure 6. The work envelope of the position sensor

\section{LabView Programming}

The computer software used was LabView, which is a trademark of National Instruments Corporation. LabView was used to display the movement responses of the gripper and also to send the voltage input of the PWM circuit. Another trademark of National Instrument Corporation used in this study was DAQ card. DAQ card used was PCI NI-6024E. The relationship between LabView, DAQ card, PWM circuit, the spring and the position sensor is illustrated in Figure 7.

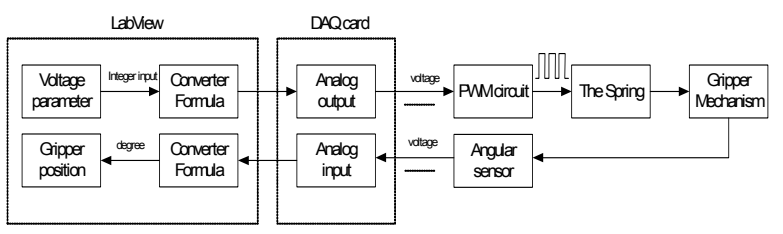

Figure 7. Block diagram of the spring actuated by PWM

\section{EXPERIMENTAL RESULTS AND DISCUSSIONS}

\section{The Power Consumption of SMA Spring}

The aim of this experiment is to obtain the distinguished characteristics of the spring power consumption between PWM and DC signal actuation. The result then to be used for diciding the appropriate signal for driving the SMA spring. In this study, the power consumption of the spring was investigated by comparing between the power consumption of the SMA spring and the resistor which has an equal size. The several frequencies of the PWM signal $(125 \mathrm{~Hz}$, $250 \mathrm{~Hz}$ and $1150 \mathrm{~Hz}$ ) and several of duty cycles were employed. The voltage power supply given was 6.0 volt and the maximum current was 3.0 Ampere.

The experimental results of current consumption are presented in Figure 8. 

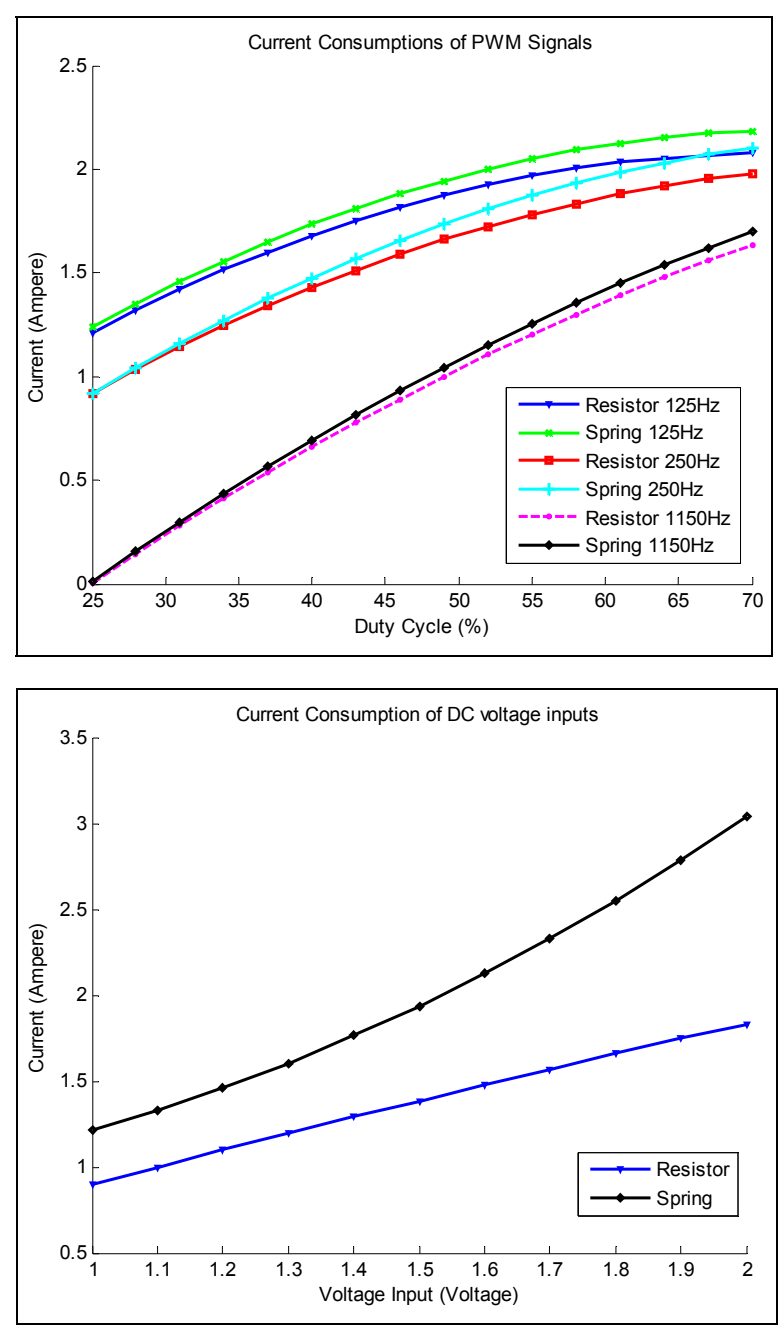

Figure 8. Current consumptions of SMA and Resistor actuated by PWM signals (top) and DC signal (bottom)

An advanced analysis was conducted by comparing the differentiation of current consumption between a resistor and the spring. These differentiations are formulated by:

Differentiation $=\frac{\text { Current_of_spring }- \text { resistor }}{\text { current_of_resistor }}$

According to the Figure 8, the distinguished characteristics of current differentiation between PWM and DC signal actuating can be calculated by using the Eq.1, and the results are depicted in Figure 9.

Refering to Figures 8 and 9, it can be analysed that the current consumption of the spring was higher than the current consumption of the resistor (actuated by DC or PWM input signals). The current consumption of $125 \mathrm{~Hz}$ and $250 \mathrm{~Hz}$ signals were likely to have the same trend. The current consumption of $125 \mathrm{~Hz}$ was higher than other frequencies at lower duty cycles, but at higher duty cycles the current consumption of
$250 \mathrm{~Hz}$ and $1150 \mathrm{~Hz}$ were more significantly increasing than the $125 \mathrm{~Hz}$ signal. The average of current differentiations of DC signals was approximately 5 10 times than that of the PWM signals. By analyzing current differentiations it can be concluded that the current consumption of the spring can be saved by using PWM signal and the rate of change of current was small for $125 \mathrm{~Hz}$ of PWM when compared to others.
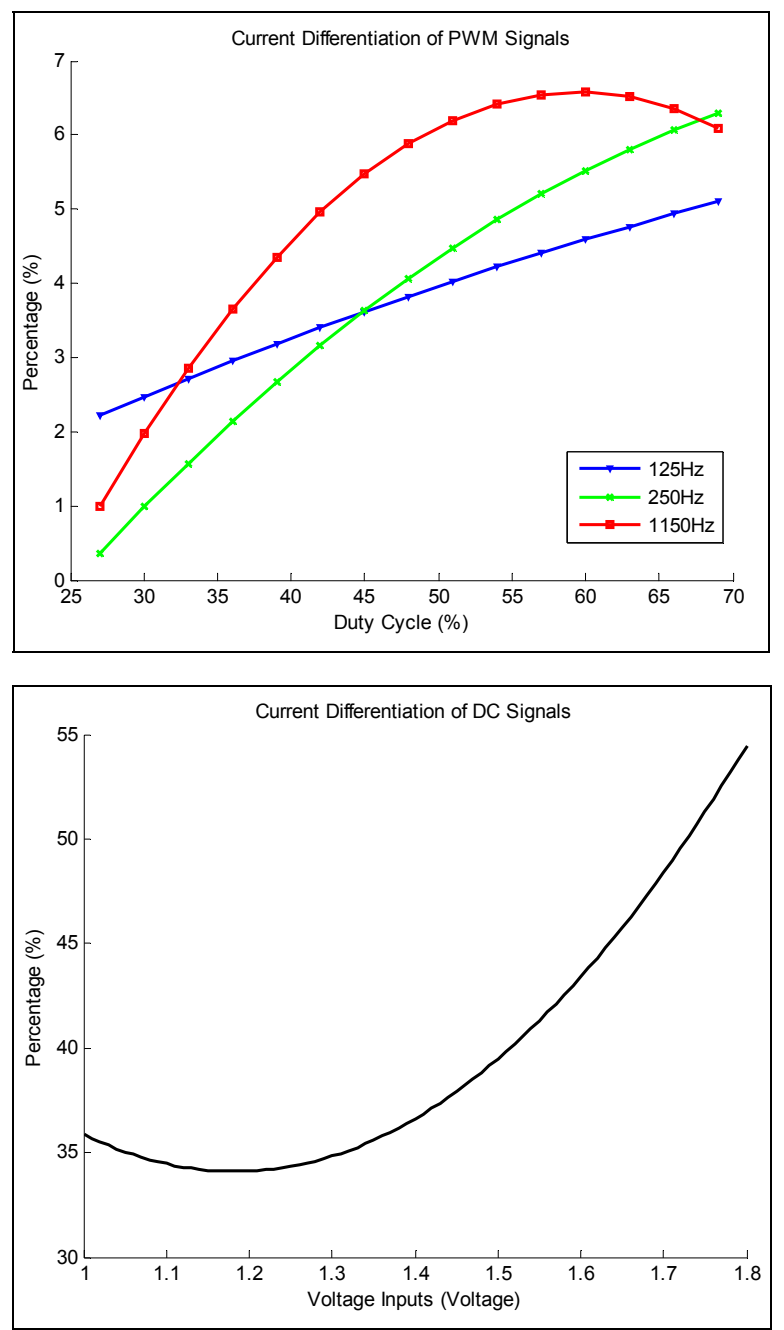

Figure 9. Current differentiation of PWM signals (top) and DC signals (bottom)

\section{The Gripper Movements}

In the previous sub chapter, the appropriate signal for driving the SMA spring has been dicided based on the smallest current consumption and rate of change. The other way of performance evaluation is to evaluate the gripper movement response actuated by different duty cycles and frequencies. The duty cycles and frequencies employed were same with previous work. All the movements of the gripper were recorded by LabView as be depicted in Figures 2 and 4. The gipper movements response actuated by different duty 
cycles and frequencies are illustrated in Figure 10. In this experiment the maximum movement of the gripper was limited to be $10^{\circ}$ or 2.8 volt of output sensor.

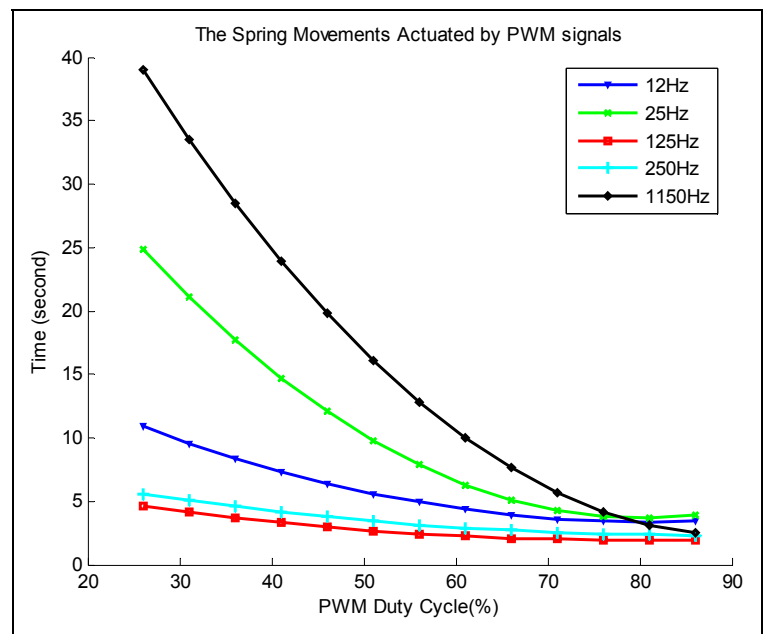

Figure 10. Spring movements actuated by several frequencies of PWM signals

Based on Figure 10, there were variation movement responses of the spring from 5 second to 40 second. The fastest responses were actuated by $125 \mathrm{~Hz}$ and $250 \mathrm{~Hz}$ of PWM signals. The other frequencies responses were 2,5 and 8 times longer than 125 or $250 \mathrm{~Hz}$. The spring movements had different responses especially at lower duty cycles. At higher duty cycles (more than $80 \%$ ), the responses of the spring were likely to be same response. The experiments result also indicated that there were no significant movements of the spring under $20 \%$ of duty cycle.

\section{The Force of the Spring}

Beside the current consumption and gripper movement, another way to evaluate the performance of the SMA spring for gripping manipulation is the force generation. The force of spring was measured by using an electronic gauge provided by Salter (Salter Electronic Gauge). Different duty cycles and frequencies were also introduced for actuating the spring as well as in the previous works. To analyse the spring force, it is necessary to determine mathematically calculation from the free body diagram. The free body diagram of the gripper is presented in Figure 11.

Based on Figure 11, the gripping force can be estimated by using formula:

$$
\begin{aligned}
& \Sigma F x=0 \\
& \Sigma F x=-F s . a+F g . b
\end{aligned}
$$

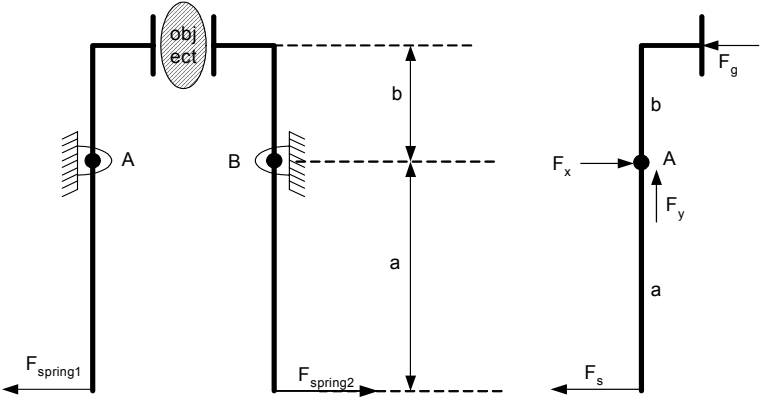

Figure 11. Free body diagram of the gripper

By substituting Eq. 2 into Eq. 3, the gripping force is obtained as

$$
F g=F s \frac{a}{b}
$$

where $\mathrm{a}=76 \mathrm{~mm}$ and $\mathrm{b}=38.5 \mathrm{~mm}$ (see Figure 4 ) and Fs is assumed to be $3 \mathrm{~N}$ maximum force (data taken from manufacturer product spesification), thus the maximum force of the single finger (without friction) is

$$
F g=3 N \frac{76 m m}{38.5 m m} \cong 5.9 N
$$

The spring force measured when the $50 \%$ and $60 \%$ of duty cycle introduced are illustrated in Figure 12.
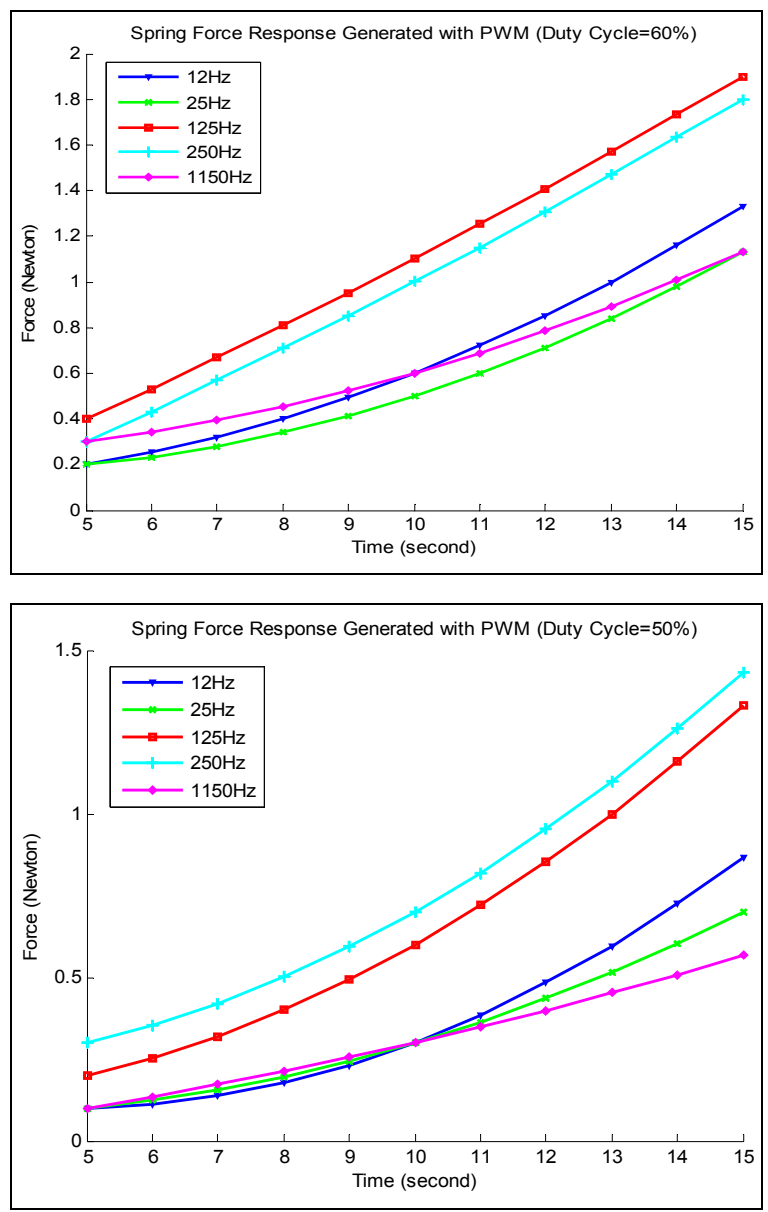

Figure 12. Spring force generated with 50\% (top) and $60 \%$ (bottom) PWM duty cycle 
According to experimental results, the fastest force generated depends on the duty cycle employed. In the lower duty cycles, the faster force generated of the spring was with a $250 \mathrm{~Hz}$ followed with $125 \mathrm{~Hz}$ and $12 \mathrm{~Hz}$ of signals. In the medium duty cycles, the fastest response was $250 \mathrm{~Hz}$ at $50 \%$ duty cycles and $125 \mathrm{~Hz}$ at $60 \%$ of duty cycle. In the higher duty cycles, the highest frequency $(1150 \mathrm{~Hz})$ was the fastest force generate and then followed with a $12 \mathrm{~Hz}$ signal. The most stabilized force was generated with a $125 \mathrm{~Hz}$ and $250 \mathrm{~Hz}$ of PWM signals. These frequencies generated spring force at the lower duty cycles whilst the other frequencies generated very small force.

\section{Close Loop Control}

In this study, a number of tests on close loop control of the gripper were conducted. The signal employed for actuating the sping was the $125 \mathrm{~Hz}$ of PWM signal due to this signal had smaller of current consumption, faster movement responses and also had more stabilized of force generated than others. The closeloop control used was the PID controller. The LabView block diagram of PID controllers is presented in Figure 13.

The gains values were limited by the maximum voltage value of PWM circuit voltage reference and DAQ card output. By determining maximum error position, the maximum value of $\mathrm{Kp}$ is

$$
\begin{aligned}
& (0.4 . \mathrm{Kp})+1.8 \leq 10 \\
& \mathrm{Kp} \leq 20.5
\end{aligned}
$$

Where 0.4 is the maximum value of position error or $\theta>15^{\circ}$ and 10 volt is the output voltage maximum of DAQ card. The value of 1.8 is the minimum voltage needed to generate the movement of the spring. The output of PID controller then can be calculated as:

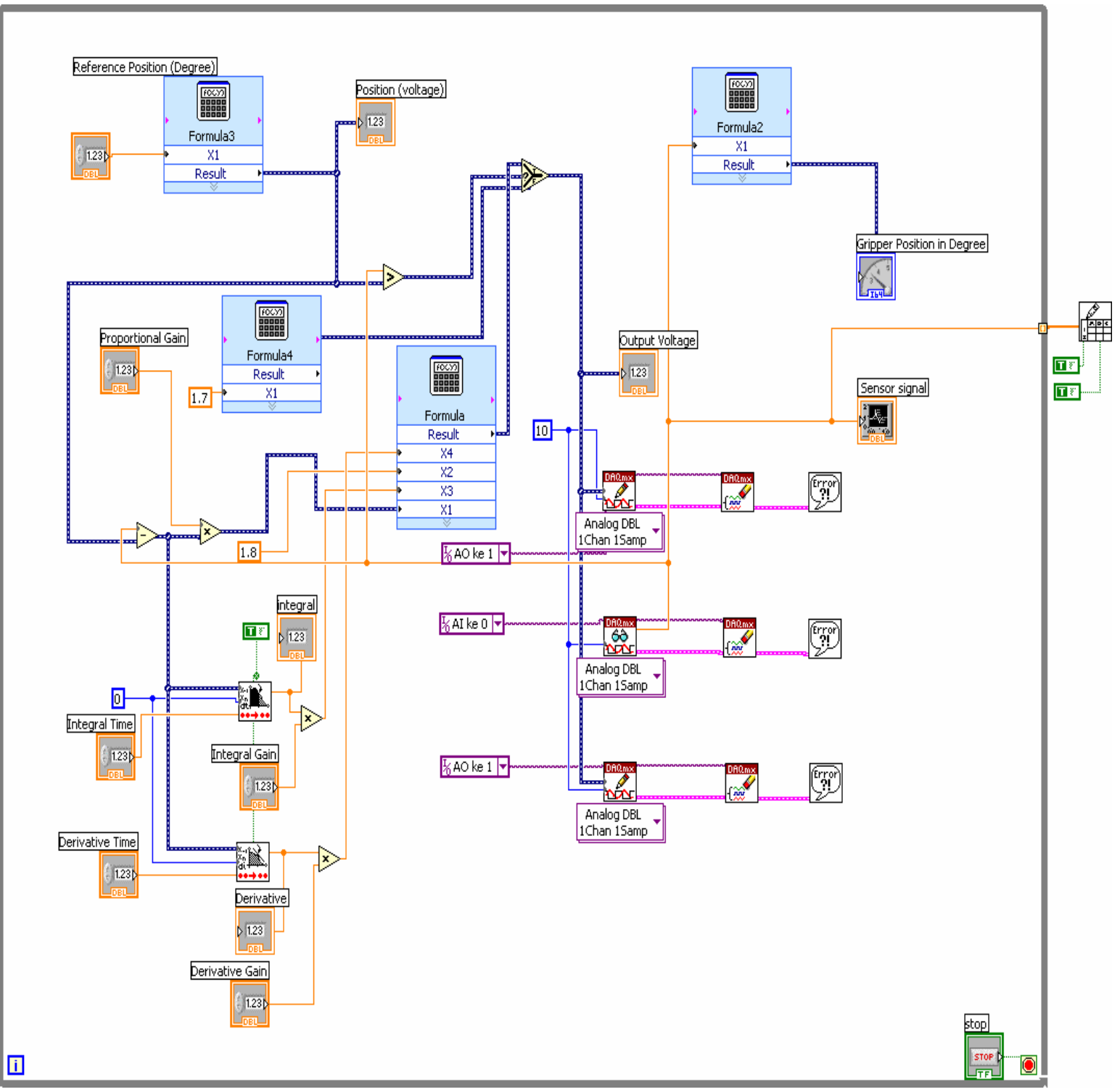

Figure 13. LabView block diagram of close loop controller 


$$
u(t)=\left[K p \cdot e(t)+K i \int_{0}^{t} e(t) \cdot d t+K d \frac{d e(t)}{d t}\right]+1.8
$$

The Ziegler-Nichols method is employed to predict the optimal closed-loop gains by using the open-loop response obtained. The optimal gains of the PID controller were determined by experimentally tuning of the gains.

The appropriate gains of PID controller obtained by using Ziegler-Nichols method are $\mathrm{Kp}$ varies from 7 to 8 , Ki varies from 0.78 to 2 and $\mathrm{Kd}$ varies from 6 to 18. According to the calculation, the gains employed were $\mathrm{Kp}=4,6,8$ and $10, \mathrm{Ki}=0.1,0.5,08,1$ and 3 and $\mathrm{Kd}=0.5,1,5,10$ and 15 .

By assuming the steady state error accepted is no more than $2 \%$, the optimal gain combinations of the PID controller is presented in Table 1 , and the response are illustrated in Figures 14, 15 and 16.

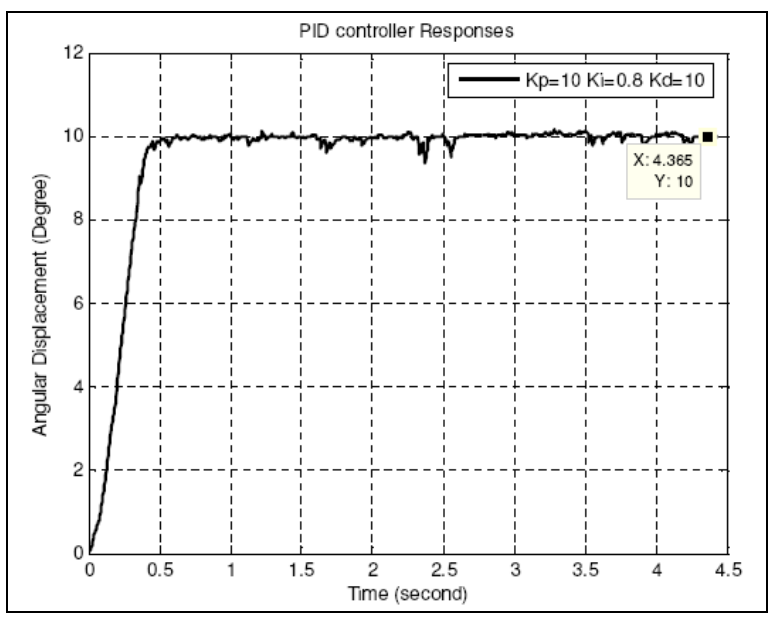

Figure 14. PID controller response with $\mathrm{Kp}=10$, $\mathrm{Ki}=0.8$ and $\mathrm{Kd}=10$.

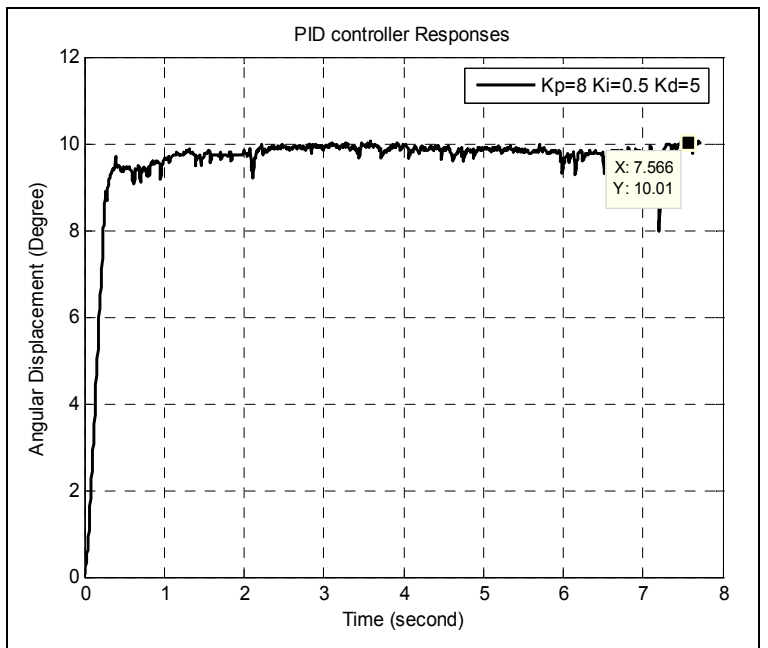

Figure 15. PID controller response with $\mathrm{Kp}=8$, $\mathrm{Ki}=0.5$ and $\mathrm{Kd}=5$.

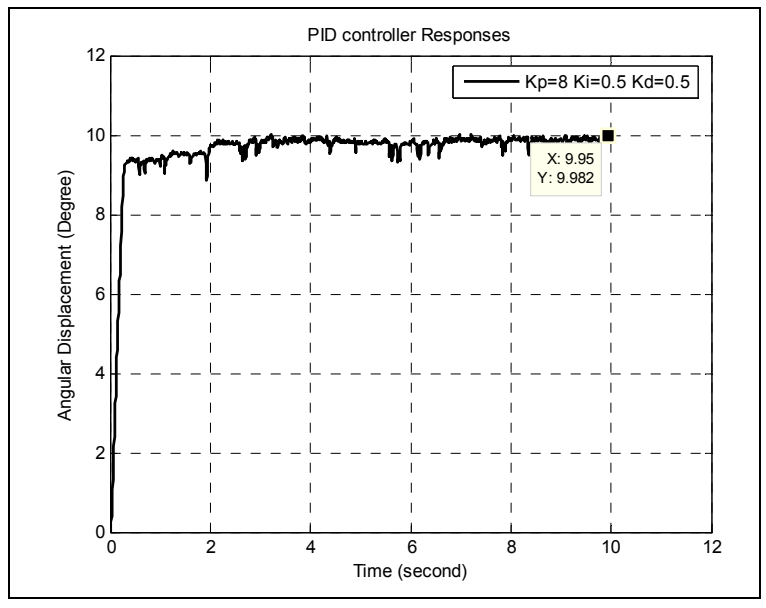

Figure 16. PID controller response with $\mathrm{Kp}=8$, $\mathrm{Ki}=0.5$ and $\mathrm{Kd}=0.5$.

Table 1. The optimal gain of PID controller for SMA spring gripper

\begin{tabular}{cccccc}
\hline No & Kp & Ki & Kd & $\begin{array}{c}\text { Rise Time } \\
\text { (second) }\end{array}$ & $\begin{array}{c}\text { Steady State } \\
\text { Error (\%) }\end{array}$ \\
\hline 1 & 6 & 1 & 0.5 & 0.2096 & $0.0 \%$ \\
2 & 8 & 0.5 & 0.5 & 0.2725 & $0.2 \%$ \\
3 & 8 & 0.5 & 5 & 0.2934 & $0.1 \%$ \\
4 & 10 & 0.8 & 10 & 0.3615 & $0.0 \%$ \\
\hline
\end{tabular}

Referring to the Table 1, the minimum steady state error is $0.0 \%$ generated with $\mathrm{Kp}=6 \mathrm{Ki}=0.5 \mathrm{Kd}=1$ and with $\mathrm{Kp}=10 \mathrm{Ki}=0.8 \mathrm{Kd}=10$. The minimum rise time of PID controller is 0.1797 second. The important things can be stated that the SMA actuator has a fast response in heating but slower in cooling, therefore the actuator has to generate moderate response to avoid steady state error. The SMA actuator movement is in one direction only. Regarding to this, the fast response in the first response and slower in the last before achieving the destination position is more durable than a faster response which can generate a steady state error. PID controller is likely a durable controller for SMA application due to has a faster response and small steady state error.

\section{CONCLUSIONS}

A number of tests on the performance evaluation of the SMA spring were conducted. The performance evaluation experiments of the SMA spring were the power consumptions experimentations, the movement response and the force generation experiments.

Generally, the current consumption of the spring was smaller when actuated by PWM signals than actuated by DC signals. The average current differentiation of the DC signals was approximately 10 times more than the PWM signals, thus it can be stated that the power consumption of the spring can be saved by using the PWM signal. The power consumption experiments were also conducted with different frequencies and different duty cycles of PWM signals. The $125 \mathrm{~Hz}$ of 
PWM signal was likely to have the smallest increasing rate of the current consumption than the $250 \mathrm{~Hz}$ and the $1150 \mathrm{~Hz}$ signals.

The gripper fabricated consists of two fingers and each finger is actuated by a SMA spring. The finger can be moved up to $15^{\circ}$ and the total angular displacement is $30^{\circ}$. The minimum voltage needed to drive the SMA spring was 0.9 volt for DC actuation and $20 \%$ to $30 \%$ of duty cycle for PWM actuation. The movement responses of the spring varied from 5 second to 40 seconds. The fastest responses were actuated by $125 \mathrm{~Hz}$ and $250 \mathrm{~Hz}$ of PWM. The other frequencies responses were 2, 5 and 8 times longer than 125 and $250 \mathrm{~Hz}$. The spring movement had different responses especially at lower duty cycles but there was no much different at higher duty cycles (more than $70 \%$ ).

The fastest force generated of the spring depended on the duty cycle employed. The most stabilized force was generated with a $125 \mathrm{~Hz}$ and $250 \mathrm{~Hz}$ of PWM signals. These frequencies generated spring force at the lower duty cycles whilst the other frequencies generated very small force.

In this study, a number of tests on position control of the gripper were also conducted by using PID controller. The best performing signal in previous experiments was employed in position control test experiments. By introducing the closed-loop control, the rise time of the gripper system was shorter than that of the open-loop controller. The rise time of the gripper system was fast approximately $600 \%$ by using the closed-loop control (PID controller). The PID controller also decreased the steady state error of the gripper system down to $0 \%$. The PID controller is likely to be reliable and suitable controller for driving the SMA spring due to they generated a faster response and a smaller steady state error.

As a conclusion of this section, it can be stated that the $125 \mathrm{~Hz}$ of PWM signal is the the best signal for driving the TiNi SMA spring. The PID controller is likely to be suitable controller for micro-gripping positioning controller. In application, it needs more consideration in longer time retain at certain position. This fenomena is caused by the minimum voltage needed to generate heating on SMA spring, force back and response time of the gripper system.

\section{REFERENCES}

[1] William L. Benard, Harold Kahn, Arthur H. Heuer, and Michael A. Huff, "Thin-Film ShapeMemory Alloy Actuated Micropumps", Journal Of Microelectromechanical Systems, Vol. 7, No. 2, 1998, pp. 245-251.
[2] Cordova, F.G., Coronado, J.L., and Gonzhlez, A.G., "Design of an anthropomorphic finger using shape memory alloy springs", Systems, Man, and Cybernetics, IEEE SMC '99 Conference Proceedings. 1999 IEEE International Conference, Vol 2, 1999, pp.794- 799.

[3] Zhang, H., Bellouard, Y, Burdet, E., Clavel, R. , Aun-Neow, P, and Hutmacher, D.W., "Shape Memory Alloy Microgripper for Robotic Microassembly of Tissue Engineering Scaffolds", Proceedings of the IEEE International Conference on Robotics and Automation (ICRA 2004), April 2004, New Orleans, USA, Vol. 5, pp. $4918-4924$.

[4] Eiji Makino, M. Uenoyama, T. Shibata, "Flash evaporation of TiNi shape memory thin film for microactuators", Sensors and Actuators A, Vol. 71, 1998, pp. 187-192.

[5] Wolf, R.H. and Heuer, A.H., "TiNi (Shape Memory) Films on Silicon for MEMS applications", Journal of Microelectromechanical Systems, Vol. 4, Issue 4, 1995, pp. 206212.

[6] Wang, Z.G., Zu, X.T., Feng, X.D., Zhu, S., Bao J.W., and Wang, L.M., "Characteristics of twoway shape memory TiNi springs driven by electrical current", Materials and Design, Vol 25, Issue 8, 2004, pp. 699-703.

[7] P. Bruschi, A. Nannini, D. Pacia, and F. Pieri, "A method for cross-sensitivity and pull-in voltage measurement of MEMS two-axis accelerometers", Sensors and Actuators A: Physical, Vol 121, Issue 1, 2005, pp. 187-196

[8] Xie, J., Shih, J. and Tai, Y.C., "Integrated Surface-Micromachined Mass Flow Controller", Micro Electro Mechanical Systems, 2003. IEEE The Sixteenth Annual International Conference, 2003, pp.20-23.

[9] Duggirala, R. and Lal, A., "A Hybrid PZTSilicon Microvalve", Journal Of Microelectromechanical Systems, Vol. 14, Issue. 3, 2005, pp. 488-497.

[10] K. Ikuta, "Microhiniature shape memory alloy actuator," Procs. of IEEE International Conference on Robotics and Automation, 1990, Cincinnati, USA, pages 2156- 2161.

[11] Yongqing Fu, Weimin Huang, Hejun Du, Xu Huang, Junping Tan, Xiangyang Gao, "Characterization of TiNi shape-memory alloy thin films for MEMS Applications", Surface Coatings and Technology, Vol 145, 2001, pp. 107-112.

[12] Dubois, Ph., Guldimann, B., Gretillat ,M.A., and de Rooij, N. F., "Electrostatically Actuated Gas Microvalve Based On A Ta-Si-N Membrane", Micro Electro Mechanical Systems, 2001. The 14th IEEE International Conference, 2001, pp. $535-538$. 
[13] Singh, P. and Rajagopalan, J., "Fuzzy LogicBased Solar Charge Controller For Microbatteries", Photovoltaic Specialists Conference, 2000. Conference Record of the Twenty-Eighth IEEE,. 2000, pp.1726 - 1729 .

[14] Menciassi, A., Moglia, A., Gorini, S., Pernorio, G., Stefanini, C., and Dario, P., "Shape memory alloy clamping devices of a capsule for monitoring tasks in the gastrointestinal tract", Journal of Micromechanics and Microengineering, Vol.15, No 11, 2005, pp. 2045-2055.

[15] Millet, O., Bernardoni, P., Régnier, S., Bidaud, P., Tsitsiris, E., Collard, D., and Buchaillot, L., "Electrostatic actuated micro gripper using an amplification mechanism", Sensors and Actuators A: Physical, Vol.114, Issues 2-3, 2004, pp.371-378.
[16] Peirs, J., Reynaerts, D., and Van Brussel, H., “A Micro Robotic Arm For A Self Propelling Colonoscope", Proceedings of the 6th International Conference on New Actuators, 1719 June 1998, Bremen, Germany, pp. 576-579.

[17] Cecil, J., and Gobinath, N., "Development of a virtual and physical work cell to assemble microdevices", Robotics and Computer-Integrated Manufacturing, Vol. 21 , Issues 4-5, 2005, pp. 431-441.

[18] Sebastian B, Volker S, Stephanus B, "Novel micro-pneumatic actuator for MEMS", Sensors and Actuators A, Vol. 97-98, 2002, pp. 638-645

[19] Wenli Zhoua, Wen J. Li, "Micro ICPF actuators for aqueous sensing and manipulation", Sensors and Actuators A, Vol. 114, 2004, pp. 406-412. 